\title{
Organic Waste Compounds as Contaminants in Milwaukee-Area Streams
}

During 2006-9, the U.S. Geological Survey (USGS), in cooperation with the Milwaukee Metropolitan Sewerage District (MMSD), conducted a study to investigate organic waste compounds (OWCs) in Milwaukee-area streams. OWCs are ingredients and by-products of common agricultural, industrial, and household substances that can contaminate our streams

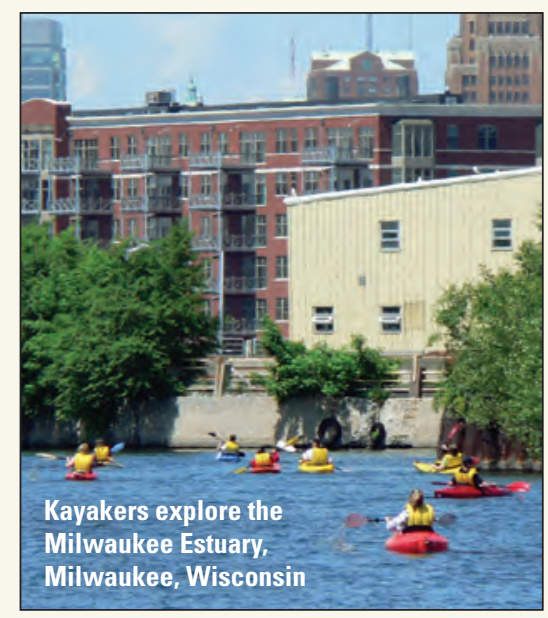

through sources like urban runoff, sewage overflows, and leaking septic systems. This fact sheet summarizes the major findings of this study; detailed information about this study and its results can be found in USGS Scientific Investigations Report 2013-5104. This study will assist watershed managers in prioritizing management and remediation

efforts by describing the occurrence, concentration, distribution, and toxicity of OWCs in Milwaukee-area streams.

Samples were collected at 12 sites (fig. 1). Three different sample types were collected: stream samples collected under normal flow conditions (base flow), water contained in the streambed (pore water), and the streambed sediment itself. Additionally, to investigate the effect of varying flow conditions, four stream sites representing varying degrees of urbanization were identified for stormflow sampling (stream samples collected during a storm)-Milwaukee River near Cedarburg
(MRC, least urban); Oak Creek at South Milwaukee (OSM); Menomonee River at Wauwatosa (MRW); and Kinnickinnic River at South 11th Street, at Milwaukee (KRM, most urban). Each water sample was tested for 69 different OWCs; each sediment sample was tested for 57 different OWCs.

\section{How Often Did We Find Organic Waste Compounds?}

All of the 196 samples collected contained at least one OWC, with as many as 41 different compounds detected in a single sample. Of the 69 compounds analyzed, 64 were detected at least once. The lowest detection rates were in baseflow samples, with a median of 12 compounds detected per sample. Stormflow, pore-water, and sediment samples had roughly twice as many detections.

The compound classes with the highest detection rates were polycyclic aromatic hydrocarbons (PAHs), insecticides, herbicides, and dyes/pigments. PAHs were the most frequently detected class overall, occurring in 100 percent of the stormflow, pore-water, and sediment samples, and in 80 percent of the base-flow samples. Detection frequencies for all classes are

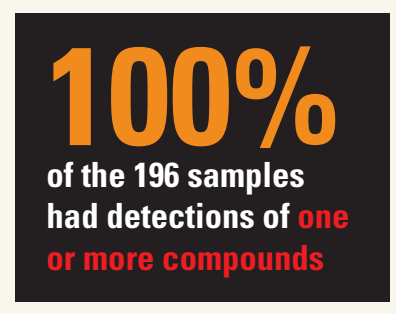
shown in figure 2.

\section{What Are Organic Waste Compounds (OWCs)?}

OWCs are ingredients and by-products of common agricultural, industrial, and household substances. For this study, 69 individual compounds were aggregated into 15 classes:
- Antioxidants
- Dyes/pigments
- Fire retardants
- Polycyclic aromatic hydrocarbons (PAHs)
- Plasticizers
- Fuels
- Solvents
- Herbicides

OWCs enter the environment in many ways, including runoff from urban and agricultural areas, industrial discharges into the air or water, leaching into the groundwater from unlined landfills, discharges from wastewatertreatment plants, combined sewer overflows, leaking septic systems, and leaking municipal sanitary and storm sewer systems.

Many of these compounds are toxic at elevated concentrations and (or) are known to have endocrine-disrupting potential. Even low concentrations can impact aquatic organisms because exposure is often chronic, spanning entire life cycles and multiple generations. Furthermore, OWCs often occur as mixtures of multiple compounds, which can strengthen their effects. 


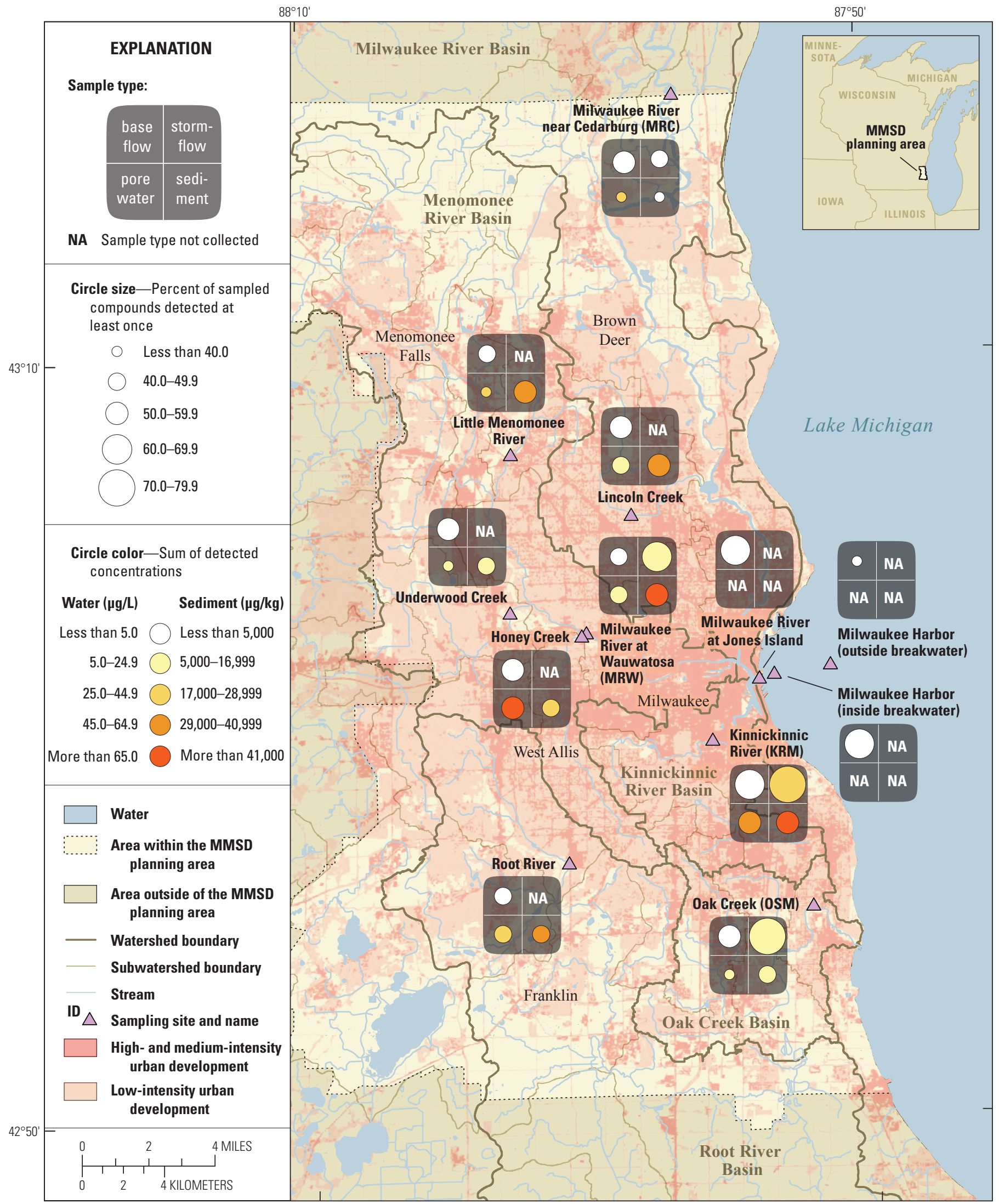

Base composited from U.S. Geological Survey National Land Cover Database 2011, 30-meter, 2011 (Jin and others, 2013); Southeastern Wisconsin Regional Planning Commission regional base map, 1:2,000, 1995; U.S. Geological Survey digital line graph hydrography, 1:100,000, 1989; Wisconsin Department of Natural Resources version 2 hydrography, 1:24,000, 2002.

Wisconsin Transverse Mercator projection, referenced to North American Datum of 1983, 1991 adjustment

Figure 1. Summary of the distribution of organic waste compounds for 12 sites in the Milwaukee Metropolitan Sewerage District (MMSD) planning area, Wisconsin. ( $\mu \mathrm{g} / \mathrm{L}$, micrograms per liter; $\mu \mathrm{g} / \mathrm{kg}$, micrograms per kilogram) 


\section{How Much Did We Find?}

The OWC classes with the highest concentrations were PAHs and herbicides. Maximum concentration values for each class can be seen below in figure 2 .

Concentrations of most compounds were higher in stormflow and pore-water samples than in base-flow samples; this was especially true of PAHs, dyes/pigments, and solvents. Stormflow sample concentrations were higher than base-flow concentrations by a factor of 2 or more for 23 compounds and by a factor of 10 or more for 5 compounds (3 PAHs, 1 solvent, and 1 flavor and fragrance). This indicates that nonpoint-source runoff and (or) wastewater leakage associated with storm events may be important sources of OWCs to the streams.

\section{Domestic Wastewater Indicators}

To identify domestic human wastewater OWC sources (for example, from leaking sanitary sewers and septic systems), a subset of 20 indicator compounds was analyzed. This group included all fire retardants and detergent metabolites, most flavors/fragrances, and triclosan (a common antimicrobial disinfectant).

Domestic wastewater indicators were detected in 100 percent of stormflow and pore-water

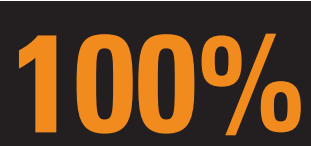

of stormflow and pore-water samples contained domestic samples, 79 percent of base-flow samples, and 89 percent of sediment samples. For base-flow and stormflow samples, the site with the highest median total concentration was KRM. Most samples showed a trend of increasing total concentrations with increasing urban area.

\section{Did We Find Potentially Toxic Amounts of Organic Waste Compounds?}

Of the 69 OWCs evaluated, 25 have known aquatic-toxicity benchmarks, and samples that exceed these benchmarks are considered potentially toxic. A benchmark indicates the value above which there is potential harm to humans or animals, but it is not a regulatory standard (U.S. Environmental Protection Agency, 2015). It is important to note that these benchmarks are based on individual compounds, rather than the complex mixtures of 20 to 40 different compounds observed in this study. Likewise, benchmarks commonly are based on exposure times of 10 days or less, whereas environmental exposure to these compounds may be measured in weeks or months. For these reasons, these single-compound benchmarks may underestimate the potential for adverse effects on aquatic organisms.

In the samples collected during this study, 13 of the 25 known benchmarks were exceeded. The compounds with the greatest benchmark exceedances were
Number of aquatictoxicity benchmarks exceeded:

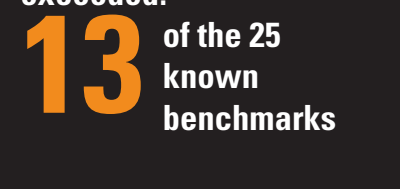
was

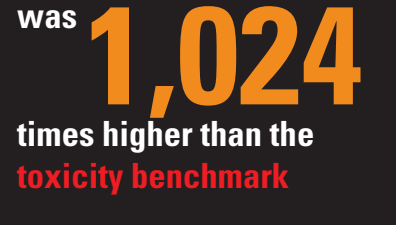

One urban PAH sample

PAHs, both in terms of exceedance frequency (up to 93 percent in sediment) and magnitude (concentrations up to 1,024 times higher than the benchmark value). Other compounds with toxicity-benchmark exceedances include individual compounds from the plasticizers, fuels, antimicrobial disinfectants, and detergent metabolites categories. Benchmark exceedances for 7 of the 13 compounds in water samples and sediment samples indicate that OWCs likely enter the stream and collect in the streambed sediments.

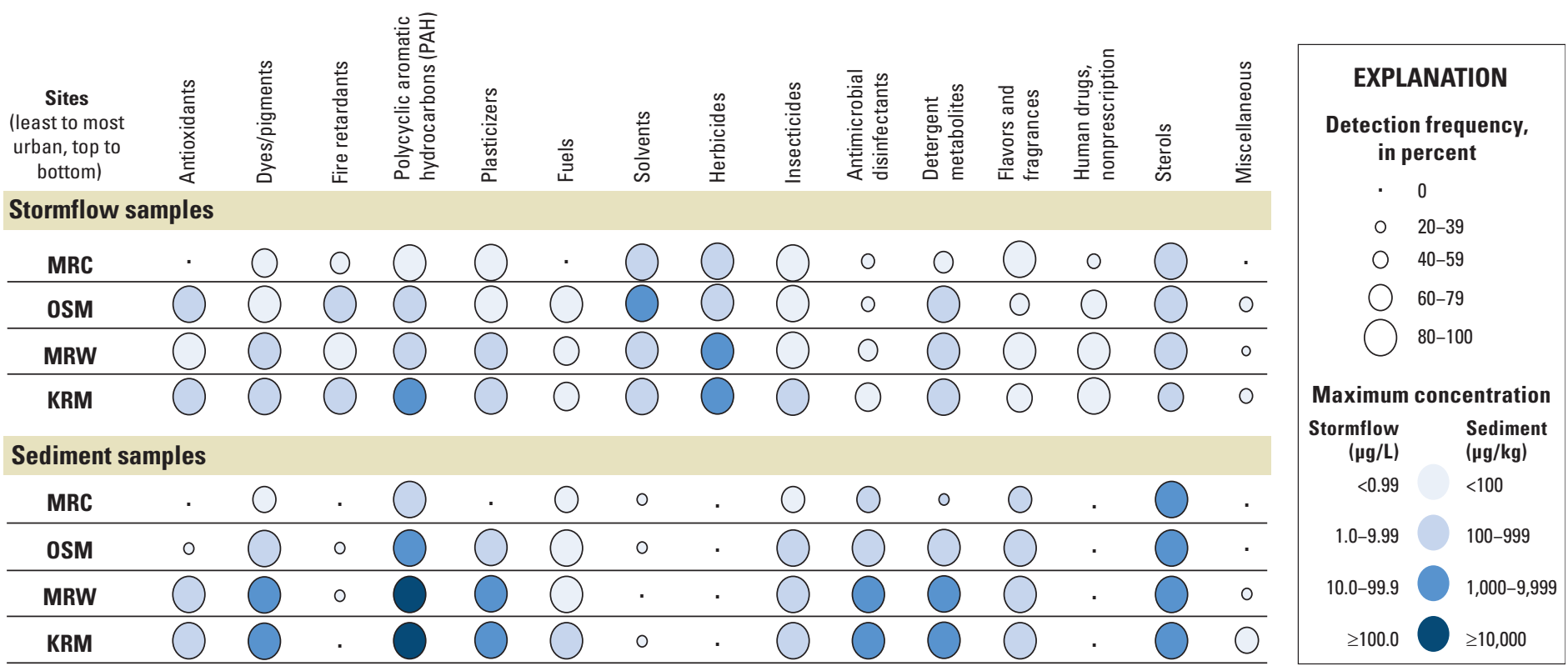

Figure 2. Detection frequency and maximum concentration by class for the four stormflow sampling sites in the Milwaukee area representing a gradient of low to high urban land use. $(<$, less than; $\geq$ greater than or equal to; $\mu \mathrm{g} / \mathrm{L}$, micrograms per liter; $\mu \mathrm{g} / \mathrm{kg}$, micrograms per kilogram) 


\section{Featured Result: Polycyclic Aromatic Hydrocarbons} (PAHs)

PAHs enter the environment through emissions from vehicles and power plants, tire particles, motor oil, creosotetreated lumber, roofing tar, coal-tar-based pavement sealants, and other sources. They break down slowly, accumulate in stream and lake sediments, and stay in the environment for long periods of time.

The PAHs were the most frequently detected class overall, occurring in 100 percent of stormflow, pore-water,

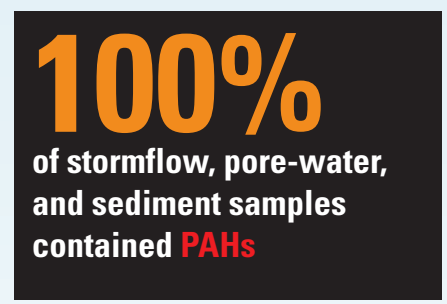
and sediment samples, and in 80 percent of base-flow samples.

In stormflow samples, $\mathrm{PAH}$ concentrations were directly related to the percentage of the basin in urban land use. The median total PAH concentration from stormflow samples at the most urban site (KRM) was 83 times higher than at the least urban site (MRC)(fig. 3).

PAH compounds were determined to be potentially toxic at 3 of 4 stormflow sites, at 4 of 9 pore-water sites, and at 7 of 9 sediment sites; but base-flow samples showed low potential for PAH toxicity. This determination indicates that PAHs are likely entering the stream through urban nonpoint runoff during storm events and accumulating in the streambed sediments.

\section{References Cited}

Jin, S., Yang, L., Danielson, P., Homer, C., Fry, J., and Xian, G., 2013, A comprehensive change detection method for updating the National Land Cover Database to circa 2011: Remote Sensing of Environment, v. 132, p. 159-175.

U.S. Environmental Protection Agency, 2015, Water Quality Benchmarks for Aquatic Life, accessed June 19, 2015, at http://www.epa.gov/bpspill/water-benchmarks.html.

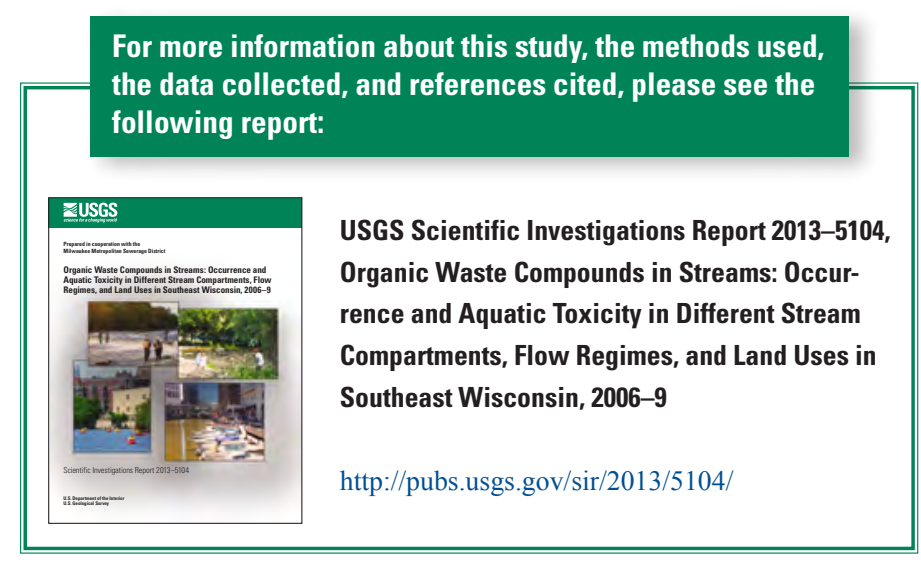

By Austin K. Baldwin, ${ }^{1}$ Steven R. Corsi, ${ }^{1}$ Christopher Magruder, ${ }^{2}$ Matthew Magruder, ${ }^{2}$ and Jennifer L. Bruce ${ }^{1}$

${ }^{1}$ U.S. Geological Survey

${ }^{2}$ Milwaukee Metropolitan Sewerage District

\section{Featured Result: Urbanization and Storm Runoff}

Urbanization increases the amount of impervious surfaces like roads and rooftops, which funnel stormwater runoff into storm sewers and prevent it from infiltrating into the ground. Structures like sanitary sewers and septic systems can suffer storm-related overflows and leaks.

To investigate the relation between OWCs, flow condition, and urbanization, we compared base-flow and stormflow samples at four sites representing an increasing gradient of urban land use. The results indicate that urban runoff and other storm-related inputs are an important source of OWCs to Milwaukee area streams:

- Compared with rural sites, urban sites exhibited higher detection frequencies, concentrations, and toxicity benchmark exceedances.

- Compared to base-flow samples, concentrations in stormflow samples were as much as 10 times higher.

- Stormflow detection frequencies averaged 1.3 to 2.0 times higher than those in base-flow samples.

- Kinnickinnic River, the most urbanized site, had the highest detection rates and concentrations of all sampled sites.

Many of these conclusions can be visualized by looking at the results for the PAH base-flow and stormflow samples (fig. 3).

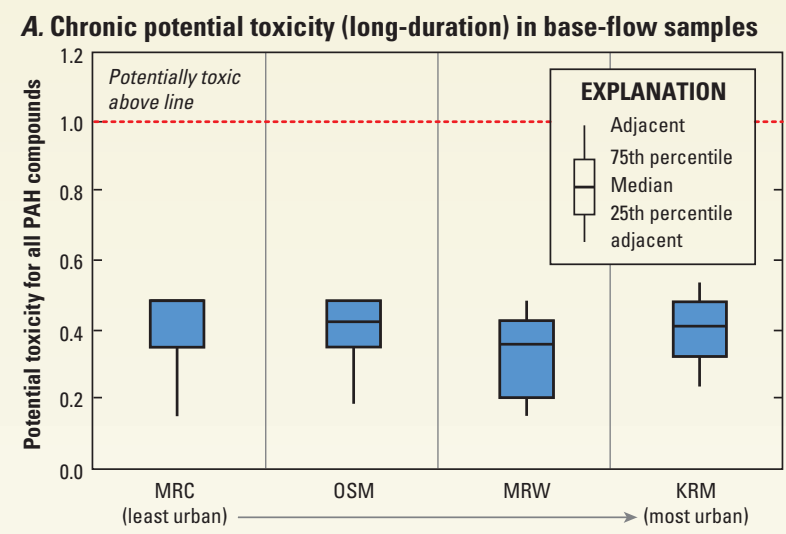

B. Acute potential toxicity (short-duration) in stormflow samples

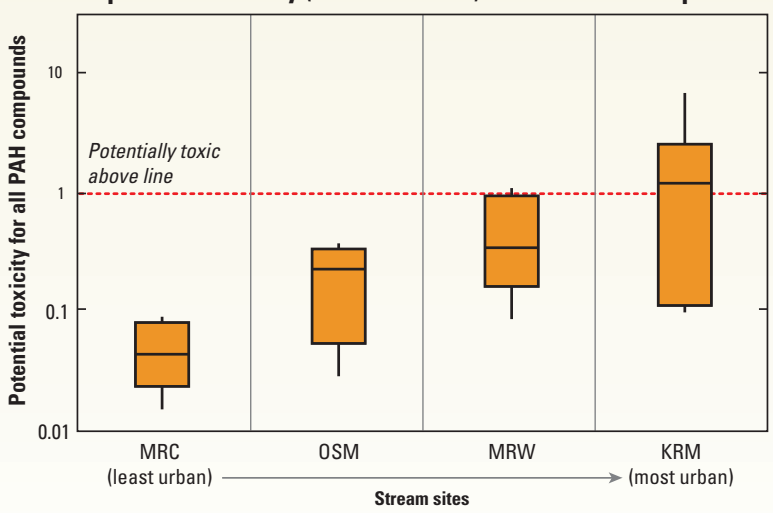

Figure 3. Polycyclic aromatic hydrocarbon (PAH) potential toxicity for base-flow and stormflow samples for the four stormflow sampling sites in the Milwaukee Area, representing a gradient of low to high urban land use. 